\title{
Metrópoles em tempos de pandemia: mapeando territórios subversivos nas RMSP e RMRJ
}

\author{
Metropolises in pandemic times: mapping subversive territories \\ in the Metropolitan Regions of São Paulo and Rio de Janeiro
}

Marcos Thimoteo Dominguez [I] Jeroen Johannes Klink [II]

\section{Resumo}

0 presente artigo analisa os atravessamentos gerados pela Covid-19 no cotidiano das periferias das metrópoles do Rio de Janeiro e de São Paulo. A crise evidenciou problemas estruturais que 0 planejamento convencional tende a obscurecer, desnudando os limites que o Estado e o capital possuem em oferecer soluções a eles. Os resultados apresentados demonstram uma relação entre a dinâmica socioespacial da Covid-19 e a estrutura hierarquizada da cidade. Partindo de provocações em torno do "planejamento subversivo", incorpora-se a dialética entre os espaços de representação e as representações do espaço (Lefebvre), identificando práticas populares e redes territoriais acionadas nas periferias, que tanto amenizaram os impactos da pandemia como permitiram ampliar o alcance das políticas urbanas e dos serviços de saúde.

Palavras-chave: Covid-19; periferias urbanas; redes sociais; Região Metropolitana do Rio de Janeiro; Região Metropolitana de São Paulo.

\begin{abstract}
This article analyzes the crossings generated by Covid-19 in the daily life of the peripheries of the metropolises of Rio de Janeiro and São Paulo. The crisis has highlighted structural problems that conventional planning tends to cover up, exposing the limits that State and capital have in providing solutions for them. The results showed a relationship between Covid-19's socio-spatial dynamics and the city's hierarchized structure. Starting with provocations around the notion of "subversive planning", the dialectic between the representation of spaces and the spaces of representation (Lefebvre) is incorporated, identifying popular practices and territorial networks that are being mobilized in the peripheries and have mitigated the impacts of the pandemic and enabled to expand the outreach of urban policies and health services.
\end{abstract}

Keywords: Covid-19; urban peripheries; social networks; Metropolitan Region of Rio de Janeiro; Metropolitan Region of São Paulo. 


\section{Introdução}

O presente artigo resulta do projeto de pesquisa Governança regional e periferias urbanas: as políticas de saneamento básico nas Regiões Metropolitanas do Rio de Janeiro e de São Pau1o, realizado no âmbito do Laboratório de Estudos e Projetos Urbanos e Regionais - Lepur, da Universidade Federal do ABC. O texto descreve importantes processos de produção do espaço urbano revisados a partir das disputas e dos conflitos sociais em torno das condições materiais básicas de reprodução social e pelo direito à vida nas metrópoles brasileiras.

A partir de um estudo comparado entre a Região Metropolitana do Rio de Janeiro (RMRJ) e a Região Metropolitana de São Paulo (RMSP), são incorporados, à análise, impactos trazidos pela Covid-19 que desnudaram ainda mais os limites que o Estado e o capital possuem em oferecer soluções a problemas urbanos complexos. Da mesma forma, foi possível confrontar o paradigma biomédico que se apoia na execução quase que exclusiva de medidas profiláticas e preventivas para lidar com a crise da Covid-19 (Castiel, 2020).

A argumentação dar-se-á em torno de duas abordagens principais, de forma a evidenciar questões estruturais para o enfrentamento da crise atual e para a reformulação do campo do planejamento urbano. Primeiro, alerta-se para as históricas condições materiais de vida nas periferias metropolitanas, enfatizando o descompasso entre a precariedade do saneamento e do acesso à água, por exemplo, e as medidas preventivas contra a Covid-19 em áreas urbanas. Um segundo ponto de argumentação é o apagamento histórico dos territórios periféricos e do espaço do vivido por parte dos projetos hegemônicos de cidade. Mas que, em tempos de pandemia, esses territórios se mobilizam e se reorganizam, buscando lidar com as múltiplas escalas do urbano, geridas predominantemente pelos grandes fluxos de capitais.

A proposta tem como suporte teórico a sociologia de Lefebvre (2013) referente à produção do espaço social, em que as contradições socioespaciais e a dialética entre escalas espaciais conformam o contexto histórico de relações entre a cidade, como espaço privilegiado para a reprodução da vida, e a cidade desigual e mercantilizada.

No que tange ao debate sobre infraestruturas e periferias metropolitanas, esse referencial irá se articular com as categorias analíticas de "redes hidrossociais" e de "multiescalaridade" trazidas por Swyngedouw (2013). Esse quadro conceitual permite questionar e incorporar, às interpretações a respeito das políticas de infraestrutura urbano, por exemplo, uma série de contestações pautadas pela dinâmica espacial e conflitual entre instituições da cidade, agentes econômicos, atores e práticas sociais.

No campo do planejamento metropolitano, autores como Randolph (2011) e Miraftab (2004) vêm provocando a revisão das bases metodológicas e conceituais por meio da proposição de um "planejamento subversivo". Incorporam as dimensões socioespaciais, temporais e comunicacionais daquilo que Habermas chamou de "mundo da vida" às discussões sobre como pensar e atuar sobre a cidade, numa tentativa de superação do planejamento convencional. De acordo com Miraftab, é preciso estimular um planejamento "conflitivo" (2016), capaz de superar a noção elaborada pela autora de "espaços de ação convidados" - que 
o Estado e as corporações praticam para criminalizar e controlar as classes subalternas - pela ideia de "espaços de ação inventados" (p. 368). Estes, não consentidos, porém conquistados pelas classes populares.

Essa perspectiva de projeto subversivo de cidade estabelece um diálogo epistemológico com as sociologias das "ausências" e das "emergências", de Sousa Santos (2010). "Enquanto a sociologia das ausências expande o domínio das experiências sociais já disponíveis, a sociologia das emergências expande o domínio das experiências sociais possíveis" (p. 120). $\mathrm{O}$ autor, ao confrontar a hegemonia do capital sobre o tempo e o espaço, defende um movimento simultâneo de dilatação do presente e de retração do futuro como estratégia de resistência à linearidade do progresso e ao apagamento das percepções de mundo para além do capitalismo.

Essa bagagem teórica auxiliará na percepção das contradições que envolveram, por exemplo, a obrigatoriedade de isolamento social e outros mecanismos de combate ao Coronavírus nos principais centros urbanos do País. A atual crise sanitária e socioeconômica intensificou e evidenciou de forma dramática o problema estrutural do desemprego e da infraestrutura urbana nas margens da cidade. Um cenário em que medidas simples, como lavar as mãos, tornaram-se desafios diante da condição de vulnerabilidade socioambiental nas periferias.

Se, de um lado, as práticas preventivas forçam a desaceleração do tempo da reprodução do capital, explícita no descompasso entre o tempo econômico (do capital) e o tempo da vida; de outro, entra em conflito com a condição de vulnerabilidade socioambiental e de radicais restrições econômicas vivenciadas pelos moradores de favela. "Como ficar em casa" nesse contexto?

No presente texto, serão apresentadas algumas estratégias territoriais e redes sociais mobilizadas por parte dos moradores de favelas nas RMRJ e RMSP, como iniciativas e medidas coletivas que visam amenizar os efeitos e as vulnerabilidades produzidas pela Covid-19. Essas experiências nas periferias, se, por um lado, resultam da dialética entre o tempo "lento" (Santos, 1994), da experiência, e o tempo da provisão, apoiados sobre a realidade social que conjuga um passado de carências e um presente de necessidades emergenciais (Valla, 1996); por outro, escancara como territórios e práticas populares vêm sendo historicamente ocultados nos planejamentos urbanos em geral, mas que insurgem e apontam para novas possibilidades de construção de espaços de representação (Lefebvre, 2013) e novos processos comunicativos entre os territórios de favelas e periferias urbanas. Lugares em que os sujeitos coletivos desenvolvem inovações tecnológicas e espaciais eficazes no enfrentamento de problemas estruturais urbanos.

Conclui-se apontando que a crise causada pela Covid-19 explicitou/atravessou dilemas antigos, mas, ao mesmo tempo, indicou espaços subversivos, potencialmente inovadores. Porém, mesmo que as redes de apoio social mapeadas amenizem o trauma vivido por trabalhadores e famílias pobres da cidade, a complexidade urbana exige mais do que reinventar a política e o planejamento metropolitano. $\mathrm{Na}$ verdade, há a necessidade de construção de um novo campo político de atuação desses atores sociais. É fundamental potencializar essas respostas territoriais periféricas, adensar 
essas redes de apoio social. É preciso garantir um ganho na capacidade de "preencher" e articular múltiplas escalas, uma nova amplitude socioespacial e comunicativa organizada em torno de problemáticas urbano-metropolitanas mais profundas.

\section{0 planejamento urbano e a produção do espaço nas margens metropolitanas}

No processo histórico de desenvolvimento urbano brasileiro, o Estado cada vez mais se tornava o ator demandado a encontrar saídas para a questão da moradia urbana e do saneamento básico (Maricato, 1982). Como reflexo, as primeiras análises científicas centravam-se ou no aspecto físico das regiões metropolitanas - espraiamento urbano, déficit de infraestrutura, etc.; ou na relação com os centros de negócio e de emprego - pendularidade, oferta de serviços, trabalho, ensino; ou na descrição das condições materiais do trabalhador - precarização da força de trabalho devido aos baixos salários, à jornada de trabalho prolongada e às vulnerabilidades socioambientais das moradias em loteamentos e favelas.

Santos (1985), numa outra perspectiva, alertava para as dificuldades na elaboração de estudos sobre regiões metropolitanas e cidades, depositando um olhar crítico sobre o urbanismo dos planejadores e tecnocratas. Para o autor, os experts em cidade tendiam a separar elementos do cotidiano que a prática e a vida social uniam por meio das experiências de vida e das diferentes formas de uso do espaço urbano. Na visão de Santos, seria preciso considerar os inúmeros elementos simbólicos e bens (i)materiais de diversas ordens que conformam a vida nas cidades. Ou seja, dar centralidade aos conflitos entre os múltiplos projetos de vida e o projeto urbanístico hegemônico.

Esse deslocamento do olhar em direção às margens exigiu um deslocamento do próprio foco de análise sobre as regiões metropolitanas. 0 desafio passa a ser identificar as interações entre as concepções distintas de normas, de condutas éticas e de práticas sociais e as escalas que alcançam. 0 espaço metropolitano, então, sintetiza e medeia essas contradições e reflete a dialética entre escalas, fluxos, tempos e territórios, todos sobrepostos, articulados e conflitantes.

Nessa direção, Randolph (2011) e Miraftab (2004) buscaram superar as iniciativas tanto do planejamento tradicional como do participativo, pois entenderam que mesmo este último continuava a reproduzir as institucionalidades e os modelos de cidade que interessavam ao capital. A dimensão espacial e temporal do urbano, nesse sentido, entraria em confronto com as estruturas estatais e de mercado que controlam a cidade. Na teoria do "planejamento subversivo", elaborada por ambos os autores, é fundamental uma nova estratégia, um novo entendimento sobre cidade:

Para discutir essas experiências como novas práticas de planejamento, necessitamos de uma nova imaginação, um novo léxico, um novo repertório de práticas e um distinto entendimento de justiça. (Miraftab, 2016, p. 367)

Diferente do consenso, previsto nas propostas progressistas de planejamento participativo/colaborativo, defende-se o campo do planejamento como ambiente de tensionamento e conflitos. Ao invés de negar as contradições entre representação do espaço 
e espaços de representação (Lefebvre, 2013), é preciso superá-las - o que não quer dizer que elas desaparecerão - de maneira a sobrepor as limitações do tempo e do espaço geradas por elas. "Sua contínua existência é de fundamental importância para que o planejamento possa cumprir essa sua função 'subversiva'" (Randolph, 2011, p. 583).

As propostas de Rainer Randolph e de Faranak Miraftab encontram diálogo teórico nas concepções sociológicas de Boaventura Sousa Santos justamente sob a ideia de que o planejamento, para se fazer práxis, precisa incorporar na sua concepção de cidade o espaço social "em sua totalidade". Ou seja, diferente da "razão indolente" ocidental criticada por Sousa Santos (2010, p. 94), que promove a "não existência" de outras concepções de mundo, a racionalidade do planejamento deve trazer na sua concepção

os espaços de representação [...] vinculados a um lado mais clandestino e subterrâneo (underground) da vida social que não obedece às regras de consistência e coesão; não envolve tanto o pensamento, mas mais os sentimentos. (Randolph, 2011, p. 580)

A falsa totalidade do planejamento hegemônico impõe uma também falsa percepção de que uma parte da cidade (a cidade do capital) representa o conjunto de todas as suas possíveis representações. 0 planejamento insurgente, de acordo com Miraftab (2016), abre portas para as ações que ultrapassam essas formas propostas pelas classes dominantes. Os "espaços de ação convidados", de participação autorizada, dariam lugar aos "espaços de ação inventados", cujas insurreições "o Estado e as corporações sistematicamente buscam colocar no ostracismo e criminalizar" (p. 368).
Nesse sentido, as práticas insurgentes apoiam-se numa "nova consciência" que libere as imaginações do planejamento" (p. 373). A transgressão do tempo linear, do progresso ocidental, permite romper com falsas dicotomias; atravessa fronteiras e ganha novas escalas; amplificando redes de solidariedade. " $\mathrm{A}$ luta central com que essa geração se defronta é entre a expansão do domínio da imaginação e o seu encerramento" (p. 373).

Essa construção de Miraftab vai ao encontro da nova racionalidade proposta por Sousa Santos, a "razão cosmopolita" (2010). Santos defende uma racionalidade apoiada na riqueza social do mundo, que supera o pragmatismo da "razão indolente" do Ocidente e, no caso aqui em voga, apresenta-se por meio de medidas preventivas e técnicas míopes e dos anseios do mercado espelhados nos planos e planejamentos de cidade. Ao defender a dilatação do presente, Santos argumenta sobre a importância do reconhecimento da diversidade de experiências de vida e de cosmologias ao longo do eixo Sul-Sul global.

Essa inversão temporal torna-se chave para subjugar a pobreza das políticas urbanas e a limitação dos planos em darem conta da diversidade social, dos conflitos, de múltiplas temporalidades e espacialidades. Essa incapacidade da razão indolente, se, por um lado, impõe sua racionalidade sobre todos, por outro, é incapaz de dar respostas aos atuais e complexos desafios urbanos. Os projetos de cidade não enquadrados, mesmo que reprimidos, conseguem movimentar-se no espaço marginal, ocupando brechas e gerando caminhos à ação política de resistência e inovadora.

Nesse sentido, pensar a cidade é pensar o encontro histórico entre o homem e sua obra, como nos salientou Lefebvre (2013). 
A empreitada teórica e empírica do autor parte das análises do estado de alienação do homem dentro da produção capitalista, mas que aponta para as mudanças e possibilidades de transformação dessas relações de produção dentro do próprio processo de produção do espaço urbano. Lefebvre, ao definir o espaço como produto social, inclui não apenas a perspectiva histórica, resultante da dialética entre temporalidades e espacialidades, mas a própria práxis. Assim, a relação Espaço-Tempo deve ser tratada como elemento essencial da prática social.

O sociólogo brasileiro José de Souza Martins, ao revisitar a dialética lefebvriana, enfatizou que justamente essa abertura de possibilidades à ação por parte de grupos sociais (populares), mesmo em ambientes altamente controlados por forças hegemônicas e opressivas, acarreta num movimento de base que é essencial para o fazer da História:

fazer história não está apenas no ato intencional de criar o novo e destruir o velho. Uma História assim é, no fundo, uma História sem tensões, sem vida, falsa história. No vivido a práxis é contraditória. Ela reproduz as relações sociais. Mas, Lefebvre observa, não há reprodução das relações sociais sem uma certa produção de relações, não há repetição sem inovação. (Martins, 1996, p. 22)

Essas perspectivas se entrecruzam por meio do encontro e do confronto das ações e projetos de vida dos diversos atores sociais com os agentes econômicos urbanos e o Estado, que, de certa forma, vão produzir diferentes territorialidades em cada contexto histórico. Lefebvre (2008; 2013), assim, descreve as dimensões da produção do espaço ao mesmo tempo individual e social, ou seja, que denotam processos ativos individuais e coletivos. Para o autor, a prática social envolve um conjunto de sentidos, sensibilidades perceptíveis do espaço. Por isso são "percebidos".

0 espaço percebido seria, no contexto da cidade, a relação do sujeito com a materialidade das coisas que estruturam o próprio urbano. Essa materialidade se dá a partir do espaço do poder hegemônico, do projeto capitalista de cidade, das "representações do espaço". Esse espaço concebido, dos experts da cidade, da estética das elites, é o espaço dominante numa sociedade e num modo de produção de momento histórico determinado.

Para Lefebvre, todas essas dimensões se chocam no ato do viver. Nesse sentido, o "espaço do vivido" entra em contradição com as principais medidas preventivas à Covid-19, por exemplo, determinadas por uma perspectiva hegemônica no campo da epidemiologia clássica (Castiel, 2020). Perspectiva esta que se apoia numa visão de saúde que restringe a dimensão social na determinação do processo saúde-doença, ou seja, que é incapaz de priorizar e articular melhorias das condições de vida, do trabalho e das estruturas sociais (Porto et al., 2014).

As disputas cotidianas pelo acesso à água nas periferias urbanas, por exemplo, dão-se no espaço do vivido por meio da experiência prática e histórica ante os problemas estruturais, que de certa forma não se deixam exaurir pela opressão do "espaço concebido". Sempre haverá um remanescente, o indizível, o "mais valioso resíduo", que só pode ser expresso por meio da prática social. 0 espaço do vivido como espaço de representação é o espaço dos "usuários", dominado e controlado, é verdade, mas que a imaginação tenta modificar e se apropriar. 
Essas percepções demonstram que nos estudos das regiões metropolitanas, sua formação, e conflitos em torno dos recursos e dos serviços urbanos por parte dos atores sociais, o espaço social deve ser tratado a partir de sua condição situacional e relacional. Com isso, não se trata apenas de reconstituí-lo historicamente, mas considerar no centro das análises as representações sociais, assim como os laços entre elas, com a própria prática social e os territórios produzidos por elas. Ou seja, há, na superfície do espaço, regulações e formas de controle estatal. Porém, no submerso da vida, há toda uma série de representações socioespaciais, redes sociais, estratégias de sobrevivência e experiências históricas e sobreposição de temporalidades.

\section{A Covid-19 e as diferentes escalas nas RMRJ e RMSP}

A chegada da pandemia ao Brasil expôs os negligenciados problemas estruturais urbanos $\mathrm{e}$ a fragilidade do sistema público de saúde em lidar com eles. A crise promoveu um ambiente de desinformação e insegurança, deixando milhares de pessoas desprotegidas por falta de ações sociais protetivas. Além disso, instaurou-se um drama socioeconômico nas favelas e periferias urbanas por conta das tentativas de adoção de medidas de isolamento social, sem estratégias coordenadas e sensíveis que pudessem garantir, à população pobre, condições mínimas de subsistência e emprego.

Um evento radical como a Covid-19 produz e reproduz situações extremas, que extrapola o tempo do evento em si, intensificando a condição de desigualdade já estabelecida historicamente pelas estruturas e hierarquias sociais (Cunha et al., 2015). No caso das infraestruturas urbanas, tal fato fica claro quando se observam a provisoriedade das políticas e a precariedade do acesso à água para fins de medidas preventivas básicas, como lavar as mãos e a limpeza periódica das moradias. Mais do que indicar as diferentes dimensões dos impactos sobre lugares e populações, o atual momento revela os limites impostos ao enfrentamento da doença e seus desdobramentos por parte das convencionais políticas de planejamento urbano.

O cotidiano, atravessado pela crise, traz à tona o conflito e uma transfiguração da realidade, indicando a necessidade de ampliação da luta social. A Covid-19, portanto, pode funcionar como um ponto de partida de análise e de observação de determinados processos que remetem ao tempo histórico das estruturas sociais e, consequentemente, das distintas possibilidades e de organização social em torno delas.

A pandemia como fenômeno socioespacial não está relacionada apenas a fatores biológicos e epidemiológicos, mas correlacionada ao espaço urbano desigual e hierarquizado. Até mesmo a definição de grupos de risco ganhou novos contornos. Em muitos lugares da cidade, a população idosa, a princípio a mais vulnerável, não é a faixa etária de maior incidência da doença e de óbitos. Nas periferias da cidade de São Paulo, por exemplo, são os jovens negros, que, por necessidade ou desinformação, não conseguem implementar a quarentena e o isolamento social (Instituto Polis, 2020a). Seu estado físico debilitado e a sua condição emocional e material, gerados por um quadro de desemprego, precariedade do trabalho e de desalento do cotidiano, tornam-nos vulneráveis à contaminação e à morte por Covid-19. 
Além disso, diferentes práticas de enfrentamento à crise trouxeram visibilidade às inúmeras redes de apoio social presentes em territórios marginais da metrópole, que passaram a ganhar novas formas diante da necessidade de respostas urgentes a problemas diários. Em um contexto de morte, essas manifestações lutam por sobrevivência, pela vida no seu sentido mais básico. Diante desse quadro, as classes populares organizaram-se para garantir elementos vitais à reprodução da vida na cidade, como comer, viver e não morrer por Covid-19.

Para a sobrevivência popular, o que há de novo é a aceleração do tempo da urgência, que passa a ser o tempo imediato. Esse descompasso temporal exige uma reestruturação rápida de redes de solidariedade e uma nova socialização. Se a pandemia, por um lado, desacelera o tempo econômico do capital, por conta do isolamento social, por outro intensifica a condição de urgência das camadas populares. Como bem salienta Sousa Santos "qualquer quarentena é sempre discriminatória" (2020, p. 15). A população, por sua vez, corre para acionar redes; realizar mutirões para coleta e distribuição de alimentos; articular-se junto aos serviços de saúde e espaços técnico-científicos para a produção e divulgação de material informativo; mobilizar-se em torno de coletivos de favelas; ampliar conectividades que dão voz aos jovens e vitalidade às comunidades pobres; além de organizar inúmeros pontos de acesso a água e materiais de limpeza para ações profiláticas básicas de prevenção ao vírus.

A sistematização dessas práticas sociais, além de desvelar as contradições do urbano e de identificar os atores sociais-chave, garante um trânsito teórico e empírico entre o local e o supralocal na dimensão da metrópole. 0 pensamento crítico, nesse caso, é essencial e deve estar sensível a esses novos tempos. É possível, então, indagar se há elementos ou atributos novos nas respostas dos territórios aos efeitos da epidemia que podem trazer elementos para a compreensão das desigualdades sociais estruturais nos espaços urbanos. Ou se, na verdade, o que há é uma radicalização da condição de vulnerabilidade socioambiental da população mais pobre, porém, que ganha certa visibilidade no atual momento de epidemia como fato social.

\section{Dimensão espaço-temporal da Covid-19 nas RMRJ e RMSP}

Em termos espaço-temporais era previsto que os casos e óbitos por Covid-19 seguissem das áreas centrais e ricas das metrópoles em direção às periferias, favelas, loteamentos e bairros populares. Tanto na RMRJ como na RMSP esse comportamento foi confirmado. Ocorreu uma mudança rápida no padrão epidemiológico e socioespacial do contágio. Se o vírus, inicialmente, entrou nos grandes centros por conta da rede de fluxos internacionais de capitais, serviços e negócios, logo passou a se disseminar a partir das estruturas urbanas desiguais, das interações entre os lugares da cidade, e a partir da condição socioeconômica e ambiental das populações.

Essa perspectiva da difusão espacial da Covid-19 parte de processos de dispersão ou propagação de um determinado evento, cuja transmissão se inicia e se difunde em um contexto específico, a partir das relações de produção e dos meios tecnológicos de informação (Sabroza, 2001). Pela ótica 
temporal, a velocidade de circulação de um agente é fortemente influenciada por seu poder de transmissibilidade e infectividade e pelas condições naturais e materiais do ambiente. Sendo assim, a presença de eixos viários de interconectividade espacial, a densidade demográfica e a precariedade na cobertura de saneamento básico são importantes parâmetros para a análise socioespacial da doença. A interação entre processos globais e condicionantes locais introduz complexidade a esses sistemas, que devem ser tratados como fenômenos multiescalares e sociais.

Após a difusão inicial, o fenômeno Covid-19 passou a compreender outros fatores que contribuíram para a distribuição espacial da doença: as péssimas condições do transporte público e a ausência de uma ação regulatória mais forte para interferir nelas; o déficit de abastecimento de água e tratamento de esgoto; o sucateamento da rede de atenção básica; a condição socioeconômica das famílias pobres; e o elevado contingente de trabaIhadores informais que estão fora dos sistemas de seguridade social e emprego. No caso das RMs em estudo, dados organizados e apresentados a seguir permitem estabelecer essa primeira interpretação do processo de difusão desigual e hierarquizado em escala metropolitana da Covid-19.

Observando as figuras, referentes à distribuição espacial dos casos na cidade do Rio de Janeiro, ainda nas primeiras semanas da pandemia em 2020, nota-se que os primeiros bairros com mais de 20 casos registrados naquele momento estavam concentrados na área litorânea e de classe média e alta da cidade (Figuras 1 e 2). Porém, na segunda quinzena de abril do mesmo ano, já era possível notar uma disseminação de casos em direção às zonas Norte e Oeste carioca, seguindo os eixos viários de integração da área central à periferia metropolitana. Se for levado em conta a taxa de letalidade, ou seja, a relação entre óbitos e casos confirmados, essa condição de desigualdade fica ainda mais exacerbada. Atualmente, a maior taxa de letalidade ${ }^{1}$ está na região popular da zona Oeste da cidade, bairros como Campo Grande e Bangu apresentaram taxas de $14,5 \%$ e $17,4 \%$, respectivamente. Enquanto a barra da Tijuca, área nobre da capital, obteve $4,9 \%$ de $\operatorname{taxa}^{2}$ (Prefeitura do Rio de Janeiro, 2021).

No caso da cidade de São Paulo, os indicadores confirmaram comportamento similar ao Rio de Janeiro. De acordo com as informações organizadas e disponibilizadas no portal do Instituto Polis (2020b) e espacializadas no painel abaixo, os óbitos por Covid-19 deslocaram-se dos bairros do centro da capital em direção aos distritos e bairros pobres do município, principalmente aqueles localizados nas zonas Norte e Leste da cidade.

A pandemia por Covid-19 expôs, assim, não apenas a desigualdade econômica e social nas grandes cidades brasileiras, mas os limites do Estado em restringir seu contínuo fluxo e difusão socioespacial. 0 quadro de injustiça socioambiental da expansão do coronavírus pelos territórios vulneráveis das metrópoles indica que se está diante, não apenas de uma crise sanitária, mas de novos limites que podem levar a uma crise humanitária, o que coloca em questão a capacidade do sistema político e das políticas urbanas em proteger a vida da população. 
Figura 1 - Casos de Covid-19 por bairros do município do Rio de Janeiro $8 / 4 / 2020$

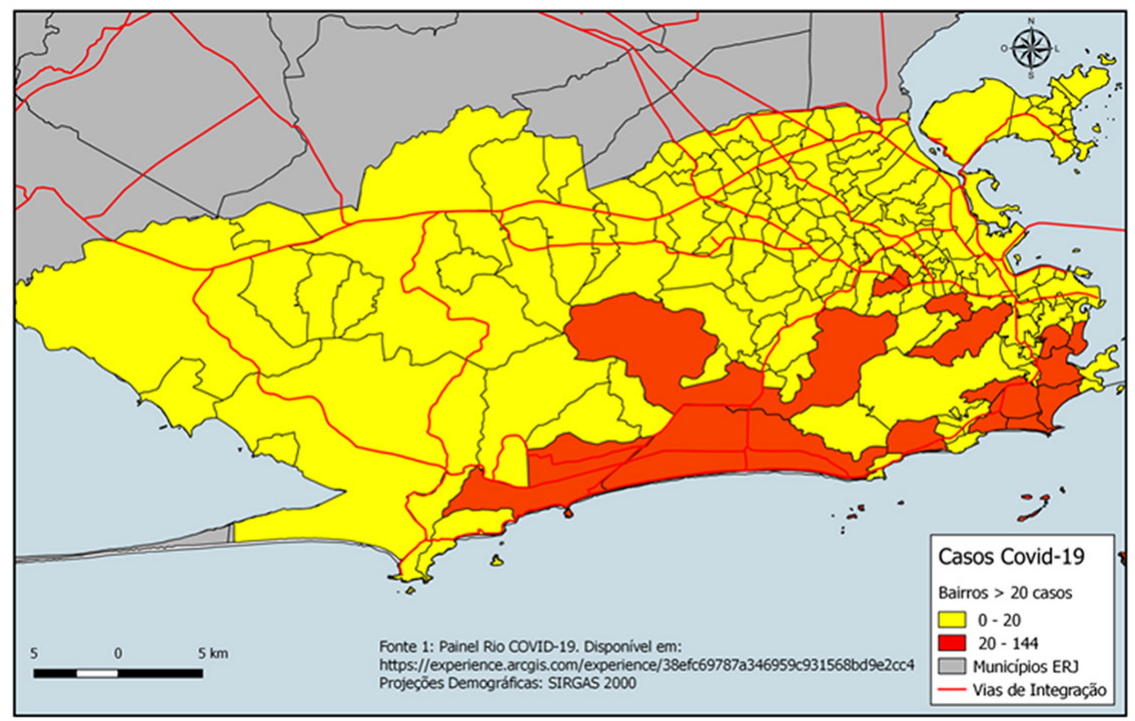

Fonte: elaboração própria a partir de Superintendência de Vigilância em Saúde/SUBPAV/SMS-RJ (Prefeitura do Rio de Janeiro, 2020).

Figura 2 - Casos de Covid-19 por bairros do município do Rio de Janeiro $23 / 4 / 2020$

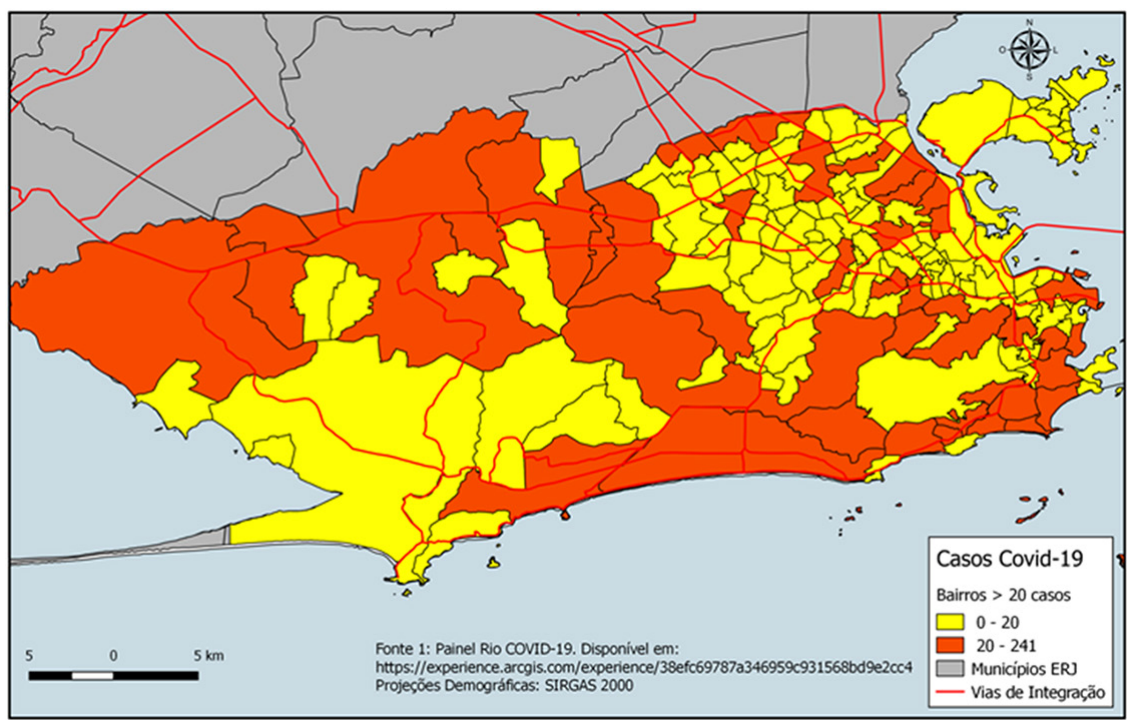

Fonte: elaboração própria a partir de Superintendência de Vigilância em Saúde/SUBPAV/SMS-RJ (Prefeitura do Rio de Janeiro, 2020). 
Figura 3 - Óbitos por Covid-19 no município de São Paulo - 2020

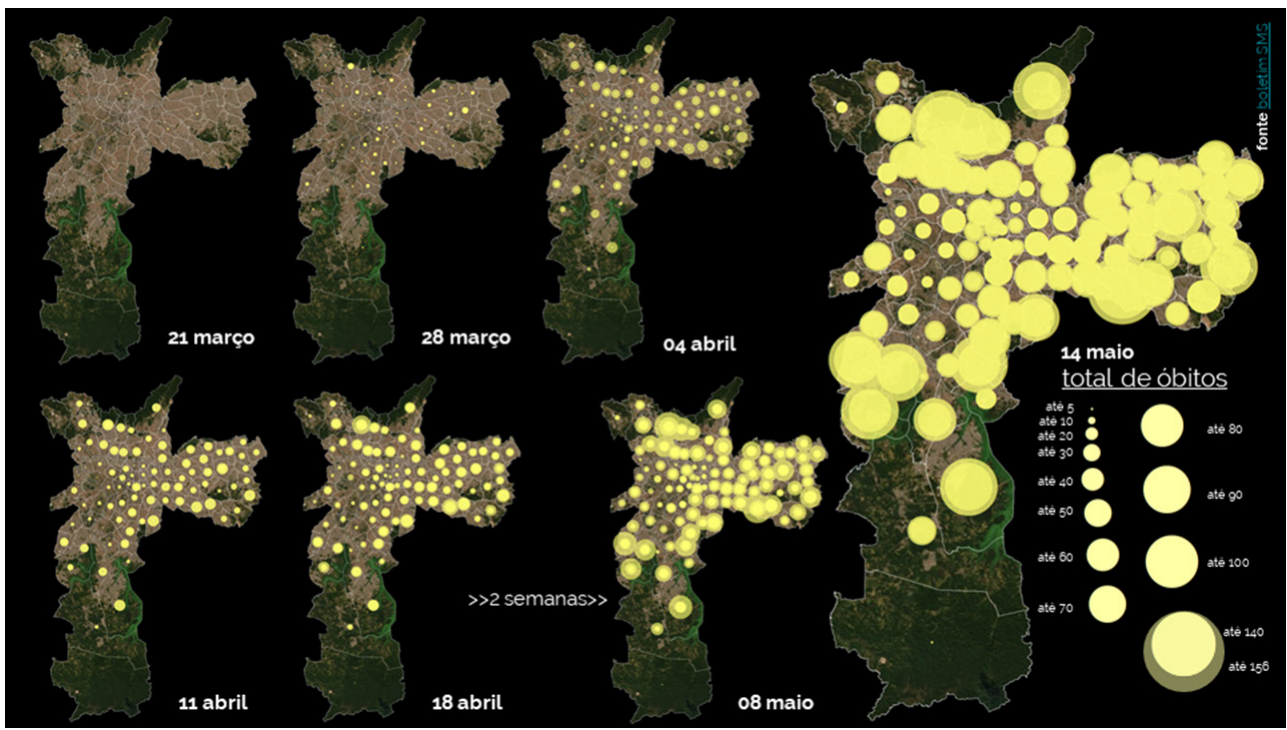

Fonte: retirado de Instituto Polis (2020b).

O conflito entre a proposição de medidas preventivas e a condição estrutural do saneamento na periferia metropolitana

No contexto atual da crise sanitária e social, o que se vê é a defesa quase que exclusiva de adoção de medidas pautadas pelas orientações do campo da epidemiologia e por determinações tecnicistas do setor de saneamento. Em muitos casos, desconectadas da realidade social e das contradições que envolvem o processo de produção do espaço nas periferias urbanas.

As políticas do setor de saneamento, historicamente, apoiam-se numa base tecnocêntrico, cujas intervenções sobre a cidade se apresentam de forma homogênea, mesmo diante de contextos diversos, e negligenciam as distintas condições sociais, culturais, ambientais e políticas locais (Heller, 2015). Da mesma forma, o setor saúde raramente é levado em consideração no processo de planejamento das intervenções ou da concepção tecnológica do saneamento.

Em trabalho anterior (Dominguez, 2018), foram analisadas algumas das relações socioespaciais construídas entre territórios metropolitanos periféricos e as políticas de infraestrutura de saneamento na RMRJ. A partir de um estudo de caso, especificamente no bairro popular de jardim Catarina, localizado no município de São Gonçalo, foi possível mapear um campo de disputa complexo em torno do 
acesso à água envolvendo moradores, agentes estatais e políticos fluminenses. Os acordos históricos e o quadro de precariedade do saneamento no jardim Catarina levaram os moradores, articulados com lideranças comunitárias, a construírem uma rede alternativa de abastecimento de água por meio de um sistema local de manobras, em parte formado por ligações clandestinas ("gatilhos") na rede oficial. ${ }^{3}$ Essa "rede marginal" de água foi o que permitiu a localidades altamente vulneráveis acessar água para o consumo básico.

Fato curioso (e contraditório) nessa história é que a segunda maior estação de tratamento de água (ETA) da RMRJ, a ETA Imunana-Laranjal, encontra-se localizada justamente no jardim Catarina. Porém, apenas a partir da década de 1990, a estação que cobre cerca de 1,5 milhão de habitantes do lado leste da baía de Guanabara (Inea, 2020) direcionou uma linha de tubulação própria para atender a algumas localidades do bairro. A presença da ETA acaba se tornando um indicador claro de injustiça socioambiental, em que um dos principais equipamentos públicos de saneamento do estado do Rio de Janeiro (ERJ) está direcionado ao atendimento das áreas centrais da metrópole. ${ }^{4}$

Em 2020, durante o seminário "Vozes da favela e da periferia sobre a Covid-19", ${ }^{5}$ realizado no segundo trimestre do ano, lideranças comunitárias do jardim Catarina reforçaram a dramática situação vivida pelo loteamento em tempos de pandemia. 0 número de casos da doença vem crescendo em paralelo à permanente angústia pela falta de saneamento no bairro: "Aqui tá tendo Covid, sim... Mas o morador não fala muito dela não. Ele continua reclamando da falta d'água. Se continuamos sem água para beber, não tem como falar em lavar a mão ou limpar a casa (Moradora do Jardim Catarina)" (Rodrigues, 2020).

No depoimento da liderança, há uma percepção mais ampla do problema, que aponta para uma sobreposição de crises que não faz separação entre a doença e a dinâmica social em que ela ocorre (Valla, 1996). A Covid-19 é vista como um fenômeno social, a solução para seu problema está atrelada à melhoria nas condições de vida local. Ignorar essa realidade social e a condição sanitária nas tratativas sobre a Covid-19 na RMRJ impede qualquer efetividade das políticas de saúde e do planejamento urbano no enfrentamento da pandemia. De concreto, desde o início da pandemia, não foi realizada nenhuma medida emergencial, seja por parte da Cedae, seja por parte da prefeitura municipal, para garantir minimamente o acesso à água como medida preventiva à Covid-19 no jardim Catarina.

Além disso, chama a atenção o fato de, em meio a uma crise sanitária e econômica, o estado do Rio de Janeiro estar decidido a aderir radicalmente às políticas neoliberais, estimuladas por instituições financeiras internacionais. O caráter de monopólio público do setor tenta ser quebrado pelo "discurso da escassez" e da eficiência, em que a produção discursiva da incapacidade do Estado e "da iminência de um desastre 'hidrossociológico' serve tanto para facilitar os investimentos na expansão do fornecimento de água, como alimenta e apoia tentativas de mercantilização" (Swyngedouw, 2013, p. 39). No quadro pandêmico atual, há um aumento de tensões e conflitos em torno do controle da água, tornando seu processo de concessão perverso, contraditório e impraticável. ${ }^{6}$ 
Para Erik Swyngedouw, porém, a organização da água por intermédio de "redes hidrossociais", que estaria em constante movimento de concentração e dispersão sobre o espaço urbano e regional, funcionaria como obstáculo ao seu controle e regulação centralizada. Por ser "um bem territorial fluído [...], a circulação hidrossocial é também um bem em rede, de constituição heterogênea, que não se presta com facilidade à homogeneização, à lógica de mercado, à mercantilização e à societarização" (Swyngedouw, 2013, p. 81). A água representa um recurso social insubstituível e em disputa, mas que exige um elevado volume de investimentos e em caráter de longo prazo. "É esse caráter de fluxo material e territorial da água que torna especialmente difícil monopolizá-la no setor privado e transformá-la numa mercadoria a ser vendida com lucro" (ibid.).

0 caso de jardim Catarina demonstra o porquê da importância de estudos sobre margens urbanas para a formulação de políticas emergências de saúde diante da crise atual. 0 que se quer dizer é que, se, por um lado, o setor de saneamento vem se abrindo cada vez mais para a apropriação financeira da água como ativo, capaz de intensificar injustiças socioambientais e desigualdades no acesso a serviços urbanos; por outro, o controle e a regulação da água estarão sob influência da organização cotidiana da cidade, que, por meio de dinâmicas territoriais e suas contradições, encontram alternativas para a reprodução da vida nas margens urbanas.

\section{Redes de apoio social e as repostas territoriais}

Logo após a eclosão da crise pandêmica, muitos grupos comunitários, coletivos de favelas e profissionais de diferentes áreas do conhecimento começaram a se mobilizar na tentativa de minimizar os impactos da pandemia nas regiões metropolitanas do país. Como estratégia de resposta aos efeitos inéditos trazidos pela Covid-19, foi mobilizado um conjunto de iniciativas e propostas que, para fins de análise, podem ser organizadas em duas linhas de ação: uma institucional e técnica, em que pesquisadores de diferentes centros de pesquisa e movimentos sociais atuam em parceria para assessorar grupos populares de favelas e de periferias urbanas no combate diário aos impactos do coronavírus. E uma segunda linha de caráter político e territorial, que historicamente é pouco reconhecida no campo do planejamento e das políticas públicas, mas que ganhou certa visibilidade em tempos de crise: as redes de apoio social nas periferias.

Em relação à primeira linha de ação, entre abril e maio de 2020, uma articulação entre centros de pesquisa, poder legislativo fluminense e coletivos de favelas do Rio de Janeiro - Complexo do Alemão, Cidade de Deus, Complexo da Maré, Rocinha, entre outros produziu e lançou o Plano de ação covid nas favelas do Rio de Janeiro: uma catástrofe a ser evitada, considerando a particular realidade desses territórios. ${ }^{7}$ Essa iniciativa reafirmou a necessidade de estabelecer ações para garantir, no campo político-institucional, recursos orçamentários para investimento social e para a execução de programas e políticas protetivas para as favelas da RMRJ.

o plano assumia, por um lado, que a cidade é um organismo estruturado por meio de fluxos, trocas e práticas sociais que moldam o espaço urbano como um fenômeno em movimento. $\mathrm{E}$, por outro, que qualquer ação que visasse inibir, bloquear ou restringir essa 
condição dinâmica poderia produzir experiências dolorosas. Termos como lockdown na favela, por exemplo, são mais carregados de contradições e conflitos do que de soluções.

No caso das favelas, há uma constituição de redes de solidariedade entre moradores e instituições comunitárias. A vida cotidiana nesses lugares avança justamente por contar com essas articulações de apoio social, que podem ser exemplificadas desde a vizinha que cuida das crianças para que as mães possam sair para trabalhar, pelos mutirões comunitários para doações de alimentos, até a organização/mobilização dos grupos populares em parceria com profissionais de saúde do SUS na execução de ações de caráter sanitário e ambiental de prevenção à pandemia.

Nesse sentido, o não reconhecimento dessas especificidades dos territórios de favelas, suas histórias e dinâmicas locais, pode reproduzir dois problemas estruturais: primeiro, corre-se o risco de maior marginalização desses espaços, tratando-os como o lugar da doença, o lugar do perigo de contaminação a ser evitado a qualquer custo. Nesse caso, as medidas prescritivas de restrição de deslocamento, ao invés de garantir bons resultados no combate à Covid-19, podem levar a um processo de segregação socioespacial da população da favela. Como consequência, há o risco de produzir maior carga de sofrimento, depositando sobre elas uma injusta responsabilidade relativa à transmissão da doença.

Um segundo problema tem a ver com a própria negação da favela e das periferias como cidade e com a história de conflito com os demais territórios urbanos e o Estado. Se não houver clareza e centralidade de que esses territórios também são Cidade e que eles, mais do qualquer outro lugar, precisam de proteção e de apoio político-institucional nesse momento de crise, há possibilidades de um tensionamento ainda maior entre esses atores e agentes.

Na RMSP, na linha de frente do combate à Covid-19, estiveram em curso inúmeras iniciativas e práticas populares de proteção social. 0 caso de Paraisópolis, ${ }^{8}$ na Zona Sul de São Paulo, tornou-se emblemático. A organização comunitária de uma das maiores favelas da capital paulista envolveu diversas estratégias coordenadas: voluntários/moradores passaram a acompanhar um número específico de famílias, uma espécie de programa de vigilância e monitoramento em saúde local. Por meio de tecnologias virtuais (grupos de WhatsApp e redes sociais), foi possível identificar famílias com casos e com distintas vulnerabilidades e acionar o próprio sistema de cobertura de saúde. ${ }^{9}$

Em menos de um mês o trabalho em Paraisópolis gerou uma extensa rede de assistência por toda a Zona Sul da capital paulista, produzindo diversos comitês comunitários e com várias frentes de ação: criação de casas de acolhimento para quarentena de moradores com suspeita de infecção pelo coronavírus; contratação de ambulâncias com equipe médica; organização de estratégias de retirada dos corpos das partes mais altas das favelas e apoio nos funerais; e desenvolvimento de ações de caráter social e econômico para apoiar trabalhadores informais sem renda.

No caso de Paraisópolis, o presente parece se expandir, refutando um futuro de fatalidade e morte. A experiência popular, nesse caso, evidencia a dialética entre a multiplicação de saberes, tempos e escalas (sociologia das ausências); e as possibilidades de ampliação simbólica e material dessas práticas (sociologia das emergências). Como nos mostrou 
Boaventura de Sousa Santos, quanto mais se amplia o universo das experiências disponíveis, mais "vasto é o campo dos sinais e das pistas credíveis e dos futuros concretos e possíveis" (Sousa Santos, 2010, p. 120).

Retornando ao município do Rio de Janeiro, inúmeras favelas e bairros da periferia também se movimentam diariamente no enfrentamento da Covid-19, dentre elas os Complexo da Maré e Manguinhos, a Rocinha, Cidade de Deus e o Alemão. Os coletivos e as comissões comunitárias, além de trabalharem para alavancar recursos e o amparo de políticas públicas, passaram a denunciar a impossibilidade de seguir as medidas de isolamento e de prevenção à Covid-19 apresentadas pelos órgãos municipais e estaduais de saúde.

No Complexo do Alemão, a mobilização entre moradores e grupos locais levou à criação de um "Gabinete de Crise", indicando a radicalização de problemas estruturais e, ao mesmo tempo, um formato organizacional capaz de aglutinar informações de forma rápida e produzir respostas (Pinheiro, 2020). É uma forma para garantir recursos materiais mínimos para os moradores e, da mesma forma, problematizar o distanciamento social em territórios cujas moradias muitas vezes contam com várias famílias convivendo na mesma habitação, e cujo modo de vida tem como fundamento a proximidade social, a vizinhança e a rua.

Outro caso emblemático de enfrentamento da epidemia por meio de ações de caráter comunicativo e de disseminação de conhecimentos mais aprofundados sobre a realidade social de favelas é a experiência da plataforma "Voz das Comunidades". Ainda em 2005, um jovem morador do Morro do Adeus, no subúrbio carioca, criou o jornal impresso $\mathrm{Voz} d a$ Comunidade. A ideia era dar visibilidade aos problemas e às particularidades da favela que não costumavam ser tratados e divulgados pelas mídias tradicionais.

Hoje, além de funcionar com uma plataforma virtual de longo alcance, contando com a participação de diversos coletivos da cidade e da Região Metropolitana do Rio de Janeiro, o Voz vem oferecendo diariamente boletins virtuais com a divulgação do número de casos e de óbitos por Covid-19 em territórios de favelas, geralmente negligenciados pelos registros oficiais do Estado. Mesmo reconhecendo a dificuldade de chegar a uma exatidão estatística, estima-se, que desde o início da pandemia, mais de 1.500 pessoas morreram em favelas cariocas (Voz das Comunidades, 2021). ${ }^{10}$

Articulados a uma rede que envolve profissionais de saúde da atenção básica, agentes comunitários de saúde e de centros de assistência social; grupos e lideranças políticas; coletivos e movimentos sociais organizados; a plataforma cobre todo o conjunto metropolitano, sistematizando informações estratégicas para o enfrentamento da epidemia, seus impactos e diversos problemas socioambientais. Trata-se de um caso paradigmático, porque instituições de pesquisa e governamentais, a exemplo da Fundação Oswaldo Cruz, ao invés de fornecer conhecimento e informação técnica, passaram a utilizar-se da plataforma comunitária para a produção de seus próprios boletins institucionais (Fiocruz, 2020a).

Além do painel "Coronavírus nas Favelas", a plataforma vem divulgando uma série de ações de coletivos e demais espaços de favela, entre eles trabalhos técnicos a exemplo do "Mapa Social Corona № 1 e 2" do Observatório de Favelas. ${ }^{11}$ Os mapas também confirmam as informações trazidas neste artigo relativas ao comportamento espacial e dispersão 
da doença e à transição epidemiológica da Covid-19 (áreas ricas > áreas pobres) sobre os territórios da cidade (Observatório de Favelas, 2020a; 2020b). 0 documento avança na análise sobre a condição desigual do espaço urbano das principais metrópoles da Região Sudeste do país, e enfatiza o desgaste social que a classes populares enfrentam historicamente nas regiões metropolitanas brasileiras diante da precariedade urbana estrutural:

Ao longo desse meio século de urbanização acelerada no país, observa-se o crescimento do número de domicílios urbanos de dois milhões para aproximadamente quarenta milhões. Entretanto, apenas $20 \%$ dessas moradias foram financiadas e/ou construídas pelo Estado. A grande parte da população urbana construiu suas residências com seus próprios recursos e esforços diante das limitações de políticas estatais de habitação e do desinteresse do mercado pelas demandas das populações de baixa renda. (Observatório de Favelas, 2020b, p. 4)

De acordo com o documento, do conjunto de pessoas que vivem em favelas e demais territórios vulneráveis, cerca de 40 milhões vivem em moradias com saneamento básico precário e, destas, 35 milhões não têm acesso à água tratada. O Mapa defende que pensar a crise causada pela Covid-19 é pensar o próprio processo de urbanização brasileira e seus efeitos. Evidencia-se, assim, que novas cartografias se tornam necessárias, e esses grupos e coletivos de favelas vêm desenvolvendo de forma sistemática conhecimento socioespacial sobre seus territórios e a cidade.

Todas essas experiências e práticas populares, além de refletir as contradições e os problemas históricos urbanos, abrem possibilidades a uma "virada comunicativa", que, nos termos de Habermas (2004), pauta-se pelas relações afetivas e consensuais a partir do "mundo da vida". Essa virada a respeito dos rumos da cidade está condicionada ao (re)conhecimento da emergência de projetos marginais, até então reféns da "não existência" (Sousa Santos, 2010). E é justamente no quadro socioeconômico e ambiental radicalizado pela pandemia Covid-19 que parece ganhar vulto certas dinâmicas territoriais atreladas tanto às especificidades dos lugares como às estruturas urbanas desiguais e hierarquizadas. São essas redes de apoio social e as pontes comunicativas entre territórios periféricos nas RMRJ e RMSP que passaram a colocar a defesa do aspecto humano no centro de um projeto contra-hegemônico em tempos de pandemia.

\section{Considerações finais}

Este artigo buscou analisar, em tempos de pandemia, as contradições que envolvem o planejamento metropolitano, as medidas preventivas estipuladas para conter a doença e os conflitos históricos entre as diferentes escalas urbanas. Seguindo as provocações de Miraftab, que nos convida a uma nova imaginação, a subversividade do planejamento dar-se-á pelo reconhecimento e pela incorporação de práticas, territórios e distintos entendimentos sobre regulação urbana e justiça nos projetos de cidade.

A dialética entre representação do espaço e espaços de representação permite compreender a cidade como produto social e como lugar relacional e conflitivo, no qual o sujeito (coletivo), mesmo em condição de 
opressão, encontra espaços de resistência e, consequentemente, de transformação da realidade social a partir da práxis. Mais do que subverter o planejamento urbano, as experiências populares aqui descritas apontam para alternativas possíveis, apoiadas nas relações de solidariedade e com a capacidade de gerar respostas emergenciais num contexto de radical crise sanitária e social.

Procurou-se problematizar os impactos da Covid-19 sobre os territórios da periferia das RMRJ e RMSP, contestando as articulações entre a hierarquia socioespacial da cidade, as condições de infraestruturas urbanas e a dinâmica espaço-temporal da pandemia. Numa cidade desigual, as redes sociais e as tecnologias populares, se, por um lado, não conseguem dar conta de toda a problemática urbana, e nem mesmo alcançam todos os territórios vulneráveis da cidade; por outro, enfrentam a frieza descontextualizada e racional das medidas preventivas contra a Covid-19. A adoção de práticas profiláticas dependentes do acesso à água e o isolamento social nas favelas tornaram-se experiências dramáticas no cotidiano pandêmico.

Em tempos de crise, o que se viu foi a intensificação de movimentos de interação e de articulação entre territórios urbanos que buscavam enfrentar problemas antigos, porém radicalizados pela pandemia. Reconhece-se um ganho de amplitude e de dimensão socioespacial a partir dessas ações, amparadas por práticas comunicativas e pela produção de novas cartografias e planos de cidade. Lugares, grupos sociais e territórios, comumente silenciados e obscurecidos pela negação dos conflitos gerada pelos planejamentos urbanos, ganham visibilidade num contexto tão adverso.
A dialética entre as dimensões socioespacial, temporal e comunicativa, exploradas ao longo do texto, aponta para a "potência" das periferias urbanas como territórios de produção de cidade e de relações contra-hegemônicas aos planos capitalistas e medidas de mercado. Uma crítica ao processo de produção do espaço da metrópole, que ilumina e inclui territórios marginais na análise sobre o urbano. Tanto a rede de gatilhos do jardim Catarina, como o comitê de crise do Morro do Alemão e as redes de apoio social de Paraisópolis, mesmo não reconhecidas no conjunto das políticas urbanas, ganham materialidade diante dos limites da ação estatal e das vulnerabilidades socioambientais urbanas.

O rompimento da invisibilidade cotidiana dessas questões estruturais evidencia uma visão superficial que esconde as diferenças socioespaciais e torna a cidade homogênea, distinta da sua real construção, historicamente constituída como o "lócus das relações contraditórias" (e conflituosas) de reprodução da força de trabalho (Castells, 1983). Na história das lutas urbanas, há inúmeros exemplos de conflitos e estratégias colocados em movimento por parte dos grupos populares. Porém, interessa destacar a atuação dessas redes populares que em momentos de crise tanto servem de suporte social e emocional como contribuem para a ampliação do alcance dos sistemas públicos de saúde e de assistência social.

As práticas populares de enfrentamento da Covid-19, além de oferecer informações mais aproximadas da realidade social, contribuem para o aprimoramento dos sistemas oficiais e públicos de monitoramento e informação. Além disso, essa convergência de saberes, estudos e metodologias pode evitar os riscos 
de marginalização das periferias, passando da posição de vulneráveis e que devem contar com proteção social, para interpretações estigmatizantes de territórios da doença, da transmissão, a serem isolados e segmentados da e pela cidade (Fiocruz, 2020b).

A verdade é que o isolamento social, como proposto, entrou em contradição com uma das principais dimensões da cidade popular, o uso coletivo do espaço. Como resistência às injustiças sociais, a solidariedade solidificada por redes de apoio social tem justamente no uso compartilhado das ruas e dos lotes parte central de sua essência. O "Fique em casa", muito propagado pelos sistemas oficiais de saúde e pelos meios de comunicação, se, por um lado, obrigou a uma redução do tempo econômico - fechando barreiras espaciais e reduzindo a intensidade das trocas comerciais -; por outro, foi feito de forma desarticulada com as dinâmicas concretas que marcam a reprodução da vida nas periferias e favelas.

Essa nova dimensão espacial imposta pela Covid-19 obriga, então, a radicalizar e ir além do projeto urbano reformista e a estruturar estratégias espaço-temporais "subversivas" que se articulam com a práxis inovadora que emerge nas periferias. Diante desse quadro, importantes debates devem ser retomados, a exemplo da constituição de fundos públicos como importante ferramenta no processo de des-mercantizalização da cidade e da financeirização da vida. Nessa nova forma de "aniquilação do tempo pelo espaço" imposta pela pandemia (Ward, 2020), as contradições entre as políticas emergenciais de prevenção e a pressão por (re)acelerar os mercados impõem a necessidade de repensar as economias metropolitanas, em geral, e a vida nas margens da cidade em particular.

\section{[i] https://orcid.org/0000-0002-8854-4031}

Universidade Federal do ABC, Centro de Engenharia, Modelagem e Ciências Sociais Aplicadas; Laboratório de Estudos e Projetos Urbanos e Regionais. São Bernardo do Campo, SP/Brasil.

marcosthdz@yahoo.com.br

\section{[II] https://orcid.org/0000-0001-6264-001X}

Universidade Federal do ABC, Centro de Engenharia, Modelagem e Ciências Sociais Aplicadas; Laboratório de Estudos e Projetos Urbanos e Regionais. São Bernardo do Campo, SP/Brasil. jeroen.klink1963@gmail.com 


\section{Notas}

(1) (Número de óbitos/Número de casos) X 100.

(2) Dados atualizados e extraídos do Painel Rio Covid-19, em 13/4/2021.

(3) Cedae - Companhia Estadual de Água e Esgoto do Rio de Janeiro.

(4) Grande parte da água tratada pela ETA Imunana-Laranjal é vendida pela Cedae à empresa "Águas de Niterói", responsável pelo abastecimento do município de mesmo nome, considerado o segundo polo econômico e administrativo da RMRJ.

(5) O seminário foi organizado por meio de uma ação colaborativa entre a disciplina "Educação popular e construção partilhada de conhecimento", da Escola Nacional de Saúde Pública da Fiocruz (ENSP/Fiocruz) e a presente pesquisa.

(6) O ERJ vive o processo de concessão de prestação regionalizada dos serviços de saneamento. Pelo Edital elaborado, com assessoria técnica do BNDES, o leilão disponibilizará para o mercado 4 blocos territoriais, envolvendo municípios fluminenses e bairros da cidade do Rio de Janeiro. No dia 28/12/2020, o Diário Oficial do ERJ publicou o decreto n. 47.422/2020, autorizando a abertura de licitação, modalidade concorrência internacional, para a concessão de serviços públicos de abastecimento de água e esgoto, por meio de uma gestão associada com o ERJ.

(7) Esse trabalho foi costurado no âmbito da Comissão de Direitos Humanos da Assembleia Legislativa do Estado do Rio de Janeiro (Alerj).

(8) De acordo com IBGE, em 2019, Paraisópolis contava com mais de 70 mil habitantes e uma densidade demográfica de $61 \mathrm{mil} \mathrm{hab} / \mathrm{km}^{2}$.

(9) Paraisópolis pertence ao distrito de vila Andrade, vizinha do bairro Morumbi. Em maio de 2020, apresentou taxa de mortalidade por Covid-19 de 21,7 óbitos por 100 mil hab. Valores abaixo da média do distrito, 30,6 por 100 mil hab. 0 indicador também está abaixo da média municipal $(56,2)$ (Instituto Polis, 2020b).

(10) Até o dia 12 de abril de 2021, o Painel indicava um total de 17.169 casos e 1.580 óbitos, em 40 favelas cariocas.

(11) Criado em 2001, o Observatório está sediado na favela da Maré, zona norte da cidade do Rio de Janeiro.

\section{Referências}

CASTELLS, M. (1983). A questão urbana. Rio de Janeiro, Paz e Terra.

CASTIEL, L. (2020). Ensaio sobre a pandemência: quando personagens e micróbios da ficção-científica saem do filme e invadem o planeta - um acompanhamento crítico de enunciados sobre a covid-19 em meios de comunicação leigos e técnicos. Observatório da Medicina. Rio de Janeiro, Fiocruz. Disponível em: http://observatoriodamedicina.ensp.fiocruz.br/wp-content/uploads/2020/05/ ENSAIO-SOBRE-A-PANDEM\%C3\%8ANCIA.pdf. Acesso em: 30 jul 2020. 
CUNHA, M. et al. (2015). O desastre no cotidiano da favela: reflexões a partir de três casos no Rio de Janeiro. O Social em Questão, ano XVIII, n. 33, pp. 95-122.

DOMINGUEZ, M. (2018). Do gatilho ao lote: as disputas pelo espaço urbano do Jardim Catarina. Tese de doutorado. Rio de Janeiro, Fundação Getúlio Vargas.

FIOCRUZ (2020a). Boletim Socioepidemiológico da Covid-19 nas Favelas. Rio de Janeiro, n. 1. Disponível em: https://portal.fiocruz.br/sites/portal.fiocruz.br/files/documentos/boletim_ socioepidemiologicos_covid_nas_favelas_1.pdf. Acesso em: 20 jul 2020.

(2020b). Covid-19 e vulnerabilidades: considerações sobre proteção social nas favelas. Nota Técnica. Rio de Janeiro. Disponível em: https://portal.fiocruz.br/documento/nota-tecnica-covid19-e-vulnerabilidades-consideracoes-sobre-protecao-social-nas-favelas. Acesso em: 3 maio 2020.

HABERMAS, J. (2004). Verdade e justificação: ensaios filosóficos. São Paulo, Loyola.

HELLER, L. (2015). “Mudanças e saneamento básico: impactos, oportunidades e desafios para o Brasil”. In: NUNES, T. et al. (orgs.). Sustentabilidade urbana: impactos do desenvolvimento econômico e suas consequências sobre o processo de urbanização em países emergentes. Brasília, MMA, v. 2.

INEA - Instituto Estadual do Ambiente (2020). Sistemas de abastecimento público de água. Disponível em: http://www.inea.rj.gov.br/ar-agua-e-solo/seguranca-hidrica/sistemas-de-abastecimento/ imunana-laranjal/. Acesso em: 3 maio 2020.

INSTITUTO POLIS (2020a). Quem são as pessoas mais afetadas pela pandemia. Dados apresentados pelo Instituto. Disponível em: https://polis.org.br/noticias/quem-sao-as-pessoas-mais-afetadaspela-pandemia/. Acesso em: 20 maio 2020.

(2020b). Paraisópolis tem melhor controle da pandemia do que o município de São Paulo. Disponível em: https://agenciagalo.com/wp-content/uploads/2020/06/Release-P\%C3\%B3lisParais\%C3\%B3polis.pdf. Acesso em: 20 maio 2020.

LEFEBVRE, H. (2008). Espaço e política. Belo Horizonte, Ed. UFMG.

(2013). La producción del espacio. Espanha, Capitan Swing.

MARICATO, E. (1982). A produção capitalista da casa (e da cidade) no Brasil industrial. São Paulo, Alfa Ômega.

MARTINS, J. (1996). As temporalidades da história na dialética de Lefebvre: Henri Lefebvre e o retorno à dialética. São Paulo, Hucitec.

MIRAFTAB, F. (2004). Invited and Invented Spaces of Participation: Neoliberal Citizenship and Feminists' Expanded Notion of Politics. Wagadu, Spring, v. 1, pp. 1-7.

(2016). Insurgência, planejamento e a perspectiva de um urbanismo humano. Revista Brasileira de Estudos Urbanos e Regionais (online). Recife, v. 18, n. 3, pp. 363-377.

OBSERVATÓRIO DE FAVELAS (2020a). Mapa Social Corona. Rio de Janeiro, n. 1. Disponível em: https:// of.org.br/acervo/mapa-social-do-corona/. Acesso em: 4 jun 2020.

(2020b). Mapa Social Corona. Rio de Janeiro, n. 2. Disponível em: https://of.org.br/acervo/ mapa-social-do-corona/. Acesso em: 4 jun 2020.

PINHEIRO, A. B. (2020). Vozes da favela e periferia sobre a Covid-19 - Cidade do Rio de Janeiro. Covid-19, o novo coronavírus. Sessão Virtual. Rio de Janeiro, ENSP/Fiocruz. Disponível em: http:// www.ensp.fiocruz.br/portal-ensp/informe/site/materia/detalhe/48839. Acesso em: 30 jul 2020. 
PORTO, M. F. S. et al. (2014). Saúde coletiva, território e conflitos ambientais: bases para um enfoque socioambiental crítico. Ciência \& Saúde Coletiva. Rio de Janeiro, v. 19, n. 10, pp. 4071-4080.

PREFEITURA DO RIO DE JANEIRO (2020). Painel Rio Covid-19. Disponível em: https://experience.arcgis. com/experience/38efc69787a346959c931568bd9e2cc4. Acesso em: 3 jun 2020.

(2021). Painel Rio Covid-19. Disponível em: https://experience.arcgis.com/experience/38efc69 787a346959c931568bd9e2cc4. Acesso em: 13 abr 2021.

RANDOLPH, R. (2011). “O choque entre expertise técnica e experiência vivida: tentativas para sua superação num planejamento subversivo". In: NATAL, J. (org.). Território e planejamento: 40 anos de IPPUR/UFRJ. Rio de Janeiro, Letra Capital, Ippur, pp. 565-590.

RODRIGUES, R. (2020). Vozes da favela e periferia sobre a Covid-19-Cidade do Rio de Janeiro. Covid-19, o novo coronavírus. Sessão Virtual. Rio de Janeiro, ENSP/Fiocruz. Disponível em: http://www. ensp.fiocruz.br/portal-ensp/informe/site/materia/detalhe/48839. Acesso em: 30 jul 2020.

SABROZA, P. (2011). Concepções de saúde e doença. Curso de especialização em avaliação em programas de controle de processos endêmicos. ESNP/Fiocruz.

SANTOS, C. N. F. (1985). Loteamentos na periferia metropolitana. Revista de Administração Municipal, jan/mar, pp. 22-39.

SANTOS, M. (1994). Técnica, espaço e tempo: globalização e meio técnico-científico informacional. São Paulo, Hucitec.

SOUSA SANTOS, B. (2010). A gramática do tempo: para uma nova cultura política. São Paulo, Cortez. (2020). A cruel pedagogia do vírus. Coimbra, Edições Almedina.

SWYNGEDOUW, E. (2013). “Águas Revoltas: a economia política dos serviços públicos essenciais”. In: HELLER, L.; ESTEBAN, J. C. Política pública e gestão de serviços de saneamento. Rio de Janeiro, Ed. Fiocruz, pp. 76-97.

VALLA, V. V. (1996). A crise da compreensão é nossa: procurando compreender a fala das classes populares. Educação e Realidade, n. 2, pp. 177-190.

VOZ DAS COMUNIDADES (2021). Coronavírus nas favelas. Disponível em: https://painel. vozdascomunidades.com.br/. Acesso em: 13 abr 2021.

WARD, C. (2020). The annihilation of time by space in the COVID-19 pandemic downturn. Dialogues in Human Geography, Commentary, pp. 1-4. 
